\title{
Depression, Aggression And Spiritual Well-Being Among The University Students In Jordan
}

\author{
Omar Ismail Alorani \\ Researcher, Department of counseling and special education \\ -Faculty of education, The University of Jordan, Amman, Jordan \\ Mu'taz Fuad Alradaydeh \\ Psychiatric mental health nurse, Health care department \\ -The University of Jordan, Amman, Jordan
}

doi: 10.19044/esj.2016.v13n2p269 URL:http://dx.doi.org/10.19044/esj.2016.v13n2p269

\begin{abstract}
Background: University students have increased levels of depression and its complications. Aggression is a serious problem among the university students in Jordan, while spiritual well-being is associated with many psychosocial issues. The purpose of this study was to identify the relationship between depression, aggression, and spiritual well-being among the university students. Methods: A quantitative approach using crosssectional descriptive-correlation design was used to carry out on convenience sample of 919 students at the University of Jordan. Results: Almost 55.7\% of the university students exhibited some degrees of depression. 51.3\% of the students reported high aggression, while $48.7 \%$ of the students reported low aggression. The Pearson correlation coefficient test showed positive correlation between depression and aggression $(\mathrm{r}=.364, \mathrm{p}<0.001)$, and negative correlation between spiritual well-being and both of depression and aggression $(\mathrm{r}=-.533, \mathrm{r}=-.288, \quad \mathrm{p}<0.001)$ respectively. Conclusions: Depression, aggression, and spiritual well-being were significantly correlated. Psychological counselors, social workers, and teachers at the universities should provide continuous psychological assessment and interventions for the students who reported high levels of aggression and depression. Spiritual well-being should be included in their interventions through various form of community services to enhance the sense of meaning of life, peace, and faith among university students.
\end{abstract}

Keywords: Aggression, depression, Jordan, spiritual well-being, university students 


\section{Introduction}

\section{Background}

University students' life is marked by a transitional period filled of psychological stressors (Hamdan-Mansour, Halabi, \& Dawani, 2008). Depression is the main psychological disturbances affected students at the university level, which is caused by living within new environment and facing different challenges such as psychological, social, and economical demands (Hamdan-Mansour \& Dawani, 2007). The literature showed that depression is one of the most important factors affected academic achievements among university students. Moreover, the prevalence of depression varies according to different factors such as measurement tools and sample characteristics (American College Health Association, 2007). According to Diagnostic and Statistical Manual of mental disorder, fifth edition (DSM 5), depression was defined as psychiatric disorder lasting for at least two weeks which include depressed mood, decrease interest, sleep or appetite disturbances, changes in the interpersonal relationships, and recurrent thinking about death (American Psychiatric Association, 2013). However, Hamdan-Mansour, Halabi, \& Dawani (2008) showed that $75 \%$ of university students in Jordan exhibited some degree of depression.

The literature had supported the relationship between depression and psychological behaviors such as aggression (Fung, Gerstein, Chan, \& Engebretson, 2015). Students at university level reported a correlation between depression and aggression (Roberts, Glod, Kim, \& Hounchell, 2010). Aggression was defined as multidimensional construct that develop within a complex interaction of biological, psychological, social, and cultural factors (Vitoratou, Ntzoufras, Smyrnis, \& Scefanis, 2009). Buss and Perry (1992) stated that aggression includes four factors: physical aggression, verbal aggression, anger, and hostility. Physical aggression or violence is defined by the Centers for Disease Control (1999) as the threatened or actual use of physical force against another person that produces physical injury or death. Verbal aggression is an attacking the self-concept of another person (Infante \& Wigley, 1986) which includes insults behaviors such as character attacks, competence attacks, teasing, ridicule, profanity, and threats. Anger implies physiological activation and represents the emotional component, and act as a psychological bridge connecting between cognitive components and violence (Buss and Perry, 1992). While hostility refers to the attitude that involves dislike and negative evaluation of others (Buss, 1961).

Mental health among university students could be affected by other factors such as spiritual well-being (Papazisis, 2014). The literature showed that depression and spiritual well-being were negatively correlated among the university students (Papazisis, 2014). Spiritual well-being is a one of core human components that reduce suffering, increase coping and promote 
mental health (Brown, Carney, Parrish, \& Klem, 2013). However, Spiritual well-being was defined according to Moberg (2002) as a sense of transcendence beyond one's circumstances, and other dimensions such as purpose of life, reliance on inner resources, and a sense of within-person integration or connectedness. Moreover, spiritual well-being has two dimensions; horizontal dimension refers to the sense of purpose in life, peace and life satisfaction, and vertical dimension refers to the sense of well-being in relation with god or higher power (Moberg, 2002). In addition, Spiritual well-being was considered as a psychological resource for coping that influence physical and psychological health (Gray, 2007). In Jordan, the literature showed that university students with grater spiritual beliefs and practices have better spiritual well-being (Musa, 2015).

Lastly, there are no studies had been conducted about the association between depression, aggression, and spiritual well-being among university students in Jordan. However, the current study aimed to examine the relationship between depression, aggression, and spiritual well-being among this population. Also, this study addresses the difference in gender and student's specialty regarding the level of depression, aggression and spiritual well-being.

\section{Methods}

\section{Design and sample}

Descriptive correlational study was conducted at the University of Jordan; which is the largest public university in Jordan, located in Amman, and includes more than thirty thousand students in all faculties (University of Jordan facts and figures, 2012). Students from various faculties were invited for participation during the academic class through invitation letter which includes the study aims, significance, data collection instructions, required time to fill the questionnaire, contact information for the researcher, and a statement informing the students that their privacy would be protected. Package of three self-reported questionnaires, in addition to the demographic data profile were distributed to the students who agreed to participate. A total of one thousand packages were distributed conveniently. Nine hundred and thirty-two students completed and returned the self-reported questionnaires, with a response rate of 93\%. After data screening, 919 questionnaires were eligible for analysis. The other questionnaires were rejected because of $50 \%$ or more of missing values.

Prior to data collection, the ethical approval was obtained from the institutional review board (IRB) in the faculty of education and deanship of academic research at the University of Jordan. To protect the individuals' identity, subject's identification number was assigned for each participant at the beginning of the study, all students understood that the participation is 
voluntary and they have the right to withdraw at any time without any penalty, and they did not face any potential risks or current benefits. All students' information was kept in locked cabinets in the researcher office.

\section{Measures}

Self-reported questionnaires were used to collect the data from the students, it includes two parts: part one the author-developed demographic profile. Part two consists the Arabic version of valid and reliable scales to measure depression, aggression, and spiritual well-being.

Depression was assessed using the Patients Reported Outcomes Measurement Information System (PROMIS) Emotional distress Depression- short form scale. It was developed by the American Psychiatric Association (APA, 2013) to monitor the pure domains of depression among individuals age 18 years or older. It includes eight items about the clinical signs of depression during the past two weeks, that primarily focused on negative mood and negative views of the self (Cella et al., 2010). Each item has five point scale ranging from "never" to "always", the total score ranges from 8 to 40. The higher scores indicate greater severity of depression. The Arabic version of PROMIS Emotional distress - Depression- short form scale was highly reliable when it was used among elderly people within the Jordanian culture with internal consistency value of .87 (Hamdan-Mansour, 2015). In this study the Cronbach's Alpha for the PROMIS Emotional distress - Depression- short form scale was 0.87 .

Spiritual well-being was measured using the Functional Assessment for Chronic Illness Therapy-spiritual well-being- non illness (FACIT-sp-non illness). It was used to measure peace/ meaning of life, and faith related to activities attempted, attitudes, and feelings experienced in the last week (Peterman et al., 2002). It includes 12 items, each item has 5-point scale ranging from "not at all" to "very much". The higher score indicate the better spiritual well-being. The FACIT- SP- non-Illness scale was translated to Arabic language, the psychometric properties results showed sufficient concurrent validity, and high reliability with internal consistency value of .72 (Lazenby et al., 2013). In this study, the Cronbach’s alpha was 0.82.

Aggression was measured using the Aggression Questionnaire (AQ) (Buss \& Perry, 1992). It is one of the most used instruments to assess aggression, it includes 29 items grouped into 4 domains, physical aggression, verbal aggression, anger, and hostility. Each item has five points scale ranging from "extremely uncharacteristic" to "extremely characteristic”. The total score of the aggression questionnaire ranges from 29 to 145 . The higher scores indicate the higher levels of aggression. The instrument was translated into Arabic by professional language editors, then the Arabic version was translated back to English by others English language professional editors. 
The two English forms, the original and the translated version, were compared. Pilot testing, using a sample of 15 university students, was conducted to evaluate the readability, comprehension and cultural appropriateness of the scale. In this study, the scale had demonstrated good internal consistency value of .85 .

Potential covariates: The demographic characteristics for the students were obtained from an investigator-developed subject profile which included age, gender, specialty, and educational years.

\section{Data analysis}

Statistical analysis was conducted using SPSS software (Statistical Package for Social Science, Version 20). Then, the data were screened for missing or impossible values using the central tendency and frequency measures. According to the level of measurement, percentages statistics were used to describe the demographic variables. Descriptive statistics (mean, median and standard deviation) were used to describe and summarize the main study variables (depression, spiritual well-being, and aggression). Reliability analysis was used to calculate internal consistency for the measures. Independent sample t-test was used to evaluate depression, spiritual well-being and aggression in relation to demographic variables. Pearson (r) correlation coefficient test was used to assess the correlation between depression, spiritual well-being, and aggression. Prior applying these tests, the assumptions such as normality and linearity were tested using skeweness, kurtosis and p-p plot.

\section{Results}

\section{Demographic data}

The sample consisted of 919 students from the University of Jordan. As showed in table 1 . Thirty three and half percent $(n=308)$ of the students were males and 66.5\% $(n=611)$ were females. Almost 36.7\% $(n=337)$ of the students were in their first academic year, while $13.3 \%(n=122)$ were in their second academic year, $27.2 \%(n=250)$ were in their third academic year and $22.8 \%(\mathrm{n}=210)$ were in their fourth academic year or more. Forty one percent $(\mathrm{n}=378)$ of the students enrolled in humanistic faculties, while $29.6 \%(n=272)$ and $29.3 \%(n=269)$ were enrolled in scientific and medical faculties, respectively. 
Table 1

Table 1: Description of sample characteristics $(\mathrm{N}=919)$

\begin{tabular}{|ccc|}
\hline variable & $\mathrm{N}(\%)$ & $\mathrm{M}(\mathrm{SD})$ \\
\hline Age & & \\
Gender & & \\
Male & $308(33.5 \%)$ & \\
Female & $611(66.5 \%)$ & \\
Educational years & $337(36.7 \%)$ & \\
First year & $122(13.3 \%)$ & \\
Second year & $250(27.2 \%)$ & \\
Third year & $210(22.8 \%)$ \\
Fourth year & $378(41 \%)$ & \\
Specialty & $272(29.6 \%)$ \\
Humanistic faculties & $269(29.3 \%)$ \\
Scientific faculties. &
\end{tabular}

\section{Depression}

The analysis showed that the mean score for PROMIS Emotional distress - Depression- short form scale was 18.0 (SD = 5.98). Approximately 44.3\% ( $\mathrm{n}=407$ ) of the students scored 16 and below on the PROMIS Emotional distress - Depression- short form scale, which indicate that those students exhibited non to slight depression. Thirty five percent $(\mathrm{n}=320)$ exhibited mild depression, 19\% ( $\mathrm{n}=176)$ exhibited moderate depression, $1.7 \%(\mathrm{n}=16)$ exhibited severe depression. The results of the independent sample t-test showed that there were no significant differences in mean scores of depression based on the students' demographic variables.

\section{Spiritual well-being}

The results showed that the mean score for FACIT-SP-12-non illness scale was 35.77 out of $48(\mathrm{SD}=7.5)$. The mean score for meaning $\mid$ peace subscale was 22.61 out of $32(\mathrm{SD}=5.37)$, while the mean score for faith subscale was 13.2 out of $16(\mathrm{SD}=3.2)$. However, the higher score of spiritual well-being scale indicates the better spiritual well-being. Studying the differences in the mean scores of spiritual well-being regarding to demographic variables, the results showed that female students had higher spiritual well-being (mean $=36.41, \mathrm{SD}=7.5$ ) than male students (mean= 34.5, $\mathrm{SD}=7.3)$, t (917) $=-3.65, \mathrm{p}=0.000$. While, there were no significant differences in the mean scores of spiritual well-being based on students' specialty and their educational year.

\section{Aggression}

Of the total samples and using the median as cut point for low and high aggression among university students, 471 (51.3\%) students reported being high aggression, while 448 (48.7\%) students were low aggression. 
The mean score for aggression was 79 (SD =15.1). studying the subscales for the aggression questionnaire showed that the mean score for the physical aggression subscale was $21.1(\mathrm{SD}=6.6)$ out of 45 , the mean score for the verbal aggression subscale was 15.0 out of $25(\mathrm{SD}=2.9)$, the mean score for the anger subscale was 20.9 out of $35(\mathrm{SD}=4.87)$, while the mean score for the hostility subscale was 21.9 out of $38(\mathrm{SD}=5.27)$. The results showed significant differences in the mean score of aggression in relation to gender, male students reported higher level of aggression (mean=83.14, SD=15.23) than female students (mean= 76.9, $\mathrm{SD}=14.65), \mathrm{t}(917)=6.02, \mathrm{p}=0.000$. Moreover, there were no significant differences in the mean scores of aggression based on students’ specialty or their educational year.

\section{Relationship between depression, spiritual well-being, and aggression}

The preliminary analyses were performed to ensure the assumptions of Person correlation test, the results showed that the variables (depression, spiritual well-being, and aggression) were met the assumptions (independency, normality, homoscedasticity, and linearity). Pearson correlation coefficient test showed that depression was positively correlated with aggression $(r=.364, \mathrm{p}<0.001)$. In addition, depression had a significant negative correlation with spiritual well-being $(\mathrm{r}=-.533, \mathrm{p}<0.001)$. This indicates that students who reported high scores of depression are more likely to report high scores of aggression and low scores of spiritual wellbeing. Lastly, the results showed significant negative correlation between total score of spiritual well-being and total score of aggression $(r=-.288$, $\mathrm{p}<0.001$ ). Table 2 presents the person ( $\mathrm{r}$ ) correlation coefficient test between the subscales of aggression (physical aggression, verbal aggression, hostility, and anger), and the subscales of spiritual well-being (meaning/peace and faith). Correlation analyses indicated that high levels of spiritual well-being (meaning/peace and faith) were associated with low levels of depression, physical aggression, verbal aggression, hostility, and anger.

\section{Table 2}

Table 2: Pearson correlation coefficient values between the subscales of aggression and the subscales of spiritual well-being.

\begin{tabular}{|c|c|c|c|c|c|}
\hline & Depression & $\begin{array}{c}\text { Physical } \\
\text { aggression }\end{array}$ & $\begin{array}{c}\text { Verbal } \\
\text { aggression }\end{array}$ & Hostility & Anger \\
\hline Depression & 1 & $.17^{* *}$ & $.15^{* *}$ & $.41^{* *}$ & $.35 * *$ \\
\hline Meaning/ peace & $-.58 * *$ & $-.21 * *$ & $-.09 * *$ & $-.36 * *$ & $\begin{array}{c}- \\
.27^{* *}\end{array}$ \\
\hline Faith & $-.27 * *$ & $-.10 * *$ & $-.01 *$ & $-.13 * *$ & $-.08 *$ \\
\hline
\end{tabular}

\section{Discussion}

This study descried the levels of depression, spiritual well-being, and aggression among the students at the University of Jordan, and it was 
investigated the relationship between depression, spiritual well-being and aggression among this population. The results showed that $55.7 \%$ of the students had mild to severe depression. The results corresponds with previous international studies, Furr, Westefeld, McConnell, and Jenkins (2001) reported that 53\% of the university students had depressive symptoms, and $40 \%$ of college students identified depression as their major concern (Woolfson,1997). Nationally, Almost 75\% of the university students exhibited some degree of depressive symptoms (Hamdan-Mansour, Halabi, Dawani, 2008). In this study, the PROMIS- Emotional distress- depressionshort form scale was used to measure the clinical signs of depression; it includes eight items about the main criteria of depression (APA, 2013). Also, it measures the negative mood, negative views for self, decrease the positive effect, and negative social cognition (Cella et al., 2010). The high levels of depression among university students could be related to social interpretation, financial challenges, or weak academic achievement (Hamdan-Mansour, Dawani, 2007). However, the prevalence of depression in the current study indicates the importance of promoting the role of university educational, social and psychological counselors.

The findings of this study showed that university students reported high means of spiritual well-being and its dimensions (meaning/ peace and faith). Moreover, the total scores of spiritual well-being had significant and negative correlation with depression, this correlation may be explained by the majority of the students were Arabs- Muslim, follow the Islamic religion, and had the same cultural and traditional lifestyle. The spiritual beliefs and practices among the students (e.g., believe that whatever happens to them is refer to god willing) was reflected the high levels of spiritual well-being dimensions (meaning/ peace, and faith). Moreover, some practices such as providing care or help for weak people, doing good deeds, and preventing bad behaviors enhance the horizontal dimension of spiritual well-being (relationship between self and others). Furthermore, praying, reading Quran, doing zakat, and doing hajj enhance the vertical dimension of spiritual wellbeing (relationship between self and god) (Musa \& Pevalin, 2012; Moberg, 2002). Therefore, the findings suggest that Muslims and Arab youth may use spiritual well-being and its dimensions (meaning/ peace, and faith) as a coping mechanism to achieve a state of peace, comfort, and psychological well-being (Musa, 2015).

Aggression was measured using combination of questions, which addressed physical aggression, verbal aggression, hostility, and anger. The current study is the first study conducted in Jordan to investigate the aggression levels among university students. The results showed that $51.3 \%$ of the students had high levels of aggression, and $48.7 \%$ of the students had low levels of aggression. While the specific dimensions of aggression among 
university students were investigated in different studies. Hamdan-mansour (2009) showed that $56 \%$ of the students at the Jordanian universities reported high levels of hostility, while 44\% reported low levels of hostility. Moreover, $73 \%$ of universities students witnessed violence inside the universities and 30\% were directly involved in the universities students' violence (Higher Youth Council, 2010). The most common causes of aggression (physical aggression, verbal aggression, anger, and hostility) among university students from the students' perspective included lack of fear from punishment, tribal fanaticism, inadequate socialization, poor investing of free times, frustration caused by low grades, weak resort to psychological and educational counseling, and weak commitment to Islamic values (Alshoraty, 2015; Al louzi\& Farhan, 2009).

The results reveled significant positive association between aggression and depression. These results corresponded with previous national study that reported a positive association between hostility and severity of depression among university students (Hamdan-Mansour, Halabi, Dawani, 2008). This association may interfere with students' abilities to express their depressed feelings in negative means, then they may use aggressive behaviors as an adaptive way to overcome their feelings and emotions (Hamdan-mansour, 2009). Moreover, negative correlation was found between aggression and spiritual well-being, which corresponded with different studies reported that forgiveness (which is one of the spirituality domains) was associated with low levels of aggression (Webb \& Dula, 2012). Therefore, spiritual well-being encourages students to be more comfort and relaxed, which allow them to provide more forgiveness and compassion, which may release the negative emotions such as anger and hostility and lead to decrease the levels of aggression (Worthington, Berry, \& Parrott, 2001). Furthermore, religion is well suited to encourage selfcontrol and self-regulation, which will motivate students to change any negative behaviors such as aggression (Webb \& Dula, 2012). In Islam religion, (which is the religion that followed by the majority of students) amnesty, forgiveness and remission to others are important values that decrease aggression and promote positive social interactions. Lastly, aggression is considered unethical and contradictory with the teachings of Islamic and Christian religions (Musa, 2015).

\section{Implications}

The current study suggests to promote the role of psychological counselors, social workers, and educational officers to provide continuous psychological assessment and interventions for the students who reported high levels of aggression and depression. There is a prompt need to implement legislations that allow psychological counselors for periodic 
psychological health assessment among the university students and promote sustainable programs to prevent occurrence of aggression. Moreover, universities can provide opportunities for students to take elective courses about psychological health and spiritual well-being. These courses should certainly consider the context of meaning of life, peace, faith, and spiritual beliefs and practices under the auspices of the holistic approach of the individual care. In addition, universities may develop extra-curricular programs to engage the students outside class rooms through offering opportunities to include them in different forms of community services. This activities will enhance the sense of meaning of life, peace, compassion, and caring for others. Furthermore, developing workshops or conferences regarding spiritual well-being and how it will influence psychological health could be an important step to decrease the provenances of depression and aggression among university students.

\section{Limitations}

Four study limitations should be noted. First, this study originated from a cross-sectional survey, so the analyses could not determine causal relationships between depression and aggression, or spiritual well-being and aggression. Longitudinal and case-control studies could be identified the potential cause-and-effect relationships between these variables. Second, the sample was limited to students at the university located in the capital city of Jordan, ignoring the students who studied in less urbanized areas. Third, the spiritual well-being is considered sensitive area of research to be assessed through self-reported questionnaires. Therefore, the students may report incomplete answers regarding the spiritual well-being questions to avoid embarrassment. Fourth, the majority of students were Muslims living in Islamic country (Jordan). Therefore, the results of the current study may not be generalized to students of other religious groups, or those in other geographical regions. Lastly, further studies among the students in different geographical areas using both qualitative and quantitative methods of data collection addressing the perceptions of spiritual well-being and psychological well-being will be informative and will increase understanding for this relationships.

\section{References:}

22. Al louzi, S. \& Farhan, Y. (2009). Students violence at the university of Jordan, Jordan Journal of Social Science, 2 (2), 277-297.

23. Alshoraty, A. (2015). Reasons for University Students' Violence in Jordan. International Education Studies; 8 (10), 150-157. 
24. American Psychiatric Association, (2013). Diagnostic and statistical manual of mental disorders - DSM-V (5th ed.). Washington, DC: American Psychiatric Association.

25. American College Health Association, (2007). National college health assessment web summary. Retrieved July 3, 2007, from http://www.acha-ncha.org/pubs_rpts.html.

26. Brown, D., Carney, J., Parrish, M., \& Klem, J. (2013). Assessing Spirituality: The Relationship between Spirituality and Mental Health. Journal of Spirituality in Mental Health, 15, 107-122.

27. Buss, A. \& Perry, M. (1992). The Aggression Questionnaire. Journal of Personality and Social Psychology, 63, 452-459.

28. Buss, A. (1961). The Psychology of Aggression. Wiley, New York.

29. Centers for Disease Control, (1999). Youth violence and suicide prevention team. Retrieved March 22, 2001 from http://www.cdc.gov/ncipc/dvp/yvpt/yvpt.htm.

30. Fung, A., Gerstein, L., Chan. Y., \& Engebretson, J. (2015). Relationship of Aggression to Anxiety, Depression, Anger, and Empathy in Hong Kong. Journal Child Family Studies, 24:821-831.

31. Furr, S., Westefeld, J., McConnell, G., \& Jenkins, J. (2001). Suicide and depression among college students: A decade later. Professional Psychology: Research and Practice, 32, 97-100.

32. Gray, J. (2007). Measuring Spirituality: Conceptual and Methodological Considerations. The Journal of Theory Construction \& Testing, 10, 85-64.

33. Hamdan-Mansour, A. (2010). Predictors of hostility among university students in Jordan, Scandinavian Journal Caring Science, 24; $125-130$.

34. Hamdan-Mansour, A., Halabi. J., \& Dawani, H. (2008). Depression, hostility, and substance use among university students in Jordan, International Journal Mental Health Addiction, 6:442-450.

35. Hamdan-Mansour, A. \& Dawani, H. (2008). Social Support and Stress among University Students in Jordan, Internal Journal Mental Health Addiction, 6:442-450.

36. Higher Youth Council. (2010). The risk factors for university violence in Jordan. Retrieved from http://www.alarrabnews.com/print.php?id=19226\&type=news.

37. Moberg, O. (2002). Assessing and measuring spirituality: Confronting dilemmas of universal and particular evaluative criteria. Journal of Adult Development, 9, 47-60.

38. Musa, A. (2015). Spiritual Beliefs and Practices, Religiosity, and Spiritual Well-Being among Jordanian Arab Muslim University 
Students in Jordan. Journal of Spirituality in Mental Health, 17 (1), 34-49.

39. Musa, A. \& Pevalin, D. (2012). An Arabic Version of the Spiritual Well-Being Scale. The International Journal for the Psychology of Religion, 22,119-134.

40. Papazisis, G., Nicolaou, P., Tsiga, E., Christoforou, T. \& SapountziKrepia, D. (2014). Religious and spiritual beliefs, self-esteem, anxiety, and depression among nursing students, Nursing and Health Sciences, 16, 232-238.

41. Roberts, J., Glod, C., Kim, R., \& Hounchell, J. (2010). Relationships between aggression, depression, and alcohol, tobacco: Implications for healthcare providers in student health. Journal of the American Academy of Nurse Practitioners, 22, 369-375.

42. Vitoratou, S., Ntzoufras, I., Smyrnis, N., \& Scefanis, N. (2009). Factorial composition of the Aggression Questionnaire: a multisample study in Greek adults. Psychiatiy Reseach, 168:32-39.

43. Woolfson, M. (1997). The effects of depression and anxiety on academic achievement. Nottingham, UK: Nottingham University.

44. Worthington, E. L., Jr., Berry, J. W., \& Parrott, L. (2001). Unforgiveness, forgiveness, religion, and health. Faith and health: Psychological perspectives. New York, NY: Guilford Press.

45. Webb, j. \& Dula, C. (2012). Forgiveness and Aggression among College Students. Journal of Spirituality in Mental Health, 14:38-58, 2012. 